\title{
Diagnóstico da exposição ocupacional a agrotóxicos na principal região produtora de pêssego para indústria do Brasil
}

\author{
Diagnosis of occupational exposure to pesticides in the main growing region of peaches \\ for the industry in Brazil
}

\author{
Crislaine Alves Barcellos de Lima ${ }^{\mathrm{I} *}$ Douglas Daniel Grützmacher ${ }^{\mathrm{I}}$ \\ Leandro Rodeghiero Krüger ${ }^{I}$ Anderson Dionei Grützmacher ${ }^{I}$
}

- NOTA-

RESUMO

A cultura do pessegueiro é bastante suscetível ao ataque de insetos praga e doenças. Para evitar prejuízos na produção, os persicultores utilizam agrotóxicos. Os objetivos deste trabalho foram caracterizar as propriedades e obter dados para melhor diagnosticar a realidade sobre a exposição ocupacional a agrotóxicos na cultura do pessegueiro. $O$ estudo baseou-se em entrevistas espontâneas, realizadas nas propriedades rurais, junto a 135 persicultores. Os resultados mostram que, de modo geral, a cultura do pessegueiro é praticada em pequenas propriedades, onde a mão-de-obra predominante é a familiar. A aquisição dos agrotóxicos é feita junto a lojas credenciadas, porém, sem receituário agronômico. Entre os agrotóxicos citados, destacam-se o fungicida Carbendazin (Derosal 500) e o inseticida (Perfekthion), que não são registrados para a cultura do pessegueiro. A utilização de equipamento de proteção individual (EPI) padrão é uma prática incomum entre os aplicadores.

Palavras-chave: produtos fitossanitários, morbidade referida, Prunus persica $L$.

\section{ABSTRACT}

The peach culture is extremely susceptible to the attack of pests and diseases. Aiming to avoid yield losses, peach growers apply pesticides. The objective of this research was to characterize some farms and obtain data to better diagnose the reality about the occupational exposition to pesticides in the peach culture. The methodology was based on spontaneous interviews carried out on farms with 135 peach growers. The results show that in general the peach culture is practiced on small farms where the predominant labor comes from the family. The purchase of agrochemicals is made via accredited shops, but without an agronomic prescription. Among the cited pesticides, the fungicide Carbendazim (Derosal 500) and insecticide (Perfekthion) are not labeled in Brazil for the peach culture. The use of personal protective equipment (PPE) standard is an uncommon practice among applicators.

Key words: agrochemicals, referred morbidity, Prunus persica $L$.

O Brasil tem grande parte da sua economia baseada na atividade agrícola, sendo 121.000 hectares cultivados com fruteiras de clima temperado. A cultura do pessegueiro ocupa uma área de aproximadamente 23.000 hectares. No Rio Grande do Sul (RS), maior produtor nacional, é possível encontrar plantas de pessegueiro em todas as regiões, sendo o Estado responsável por aproximadamente $57 \%$ da produção nacional (IBRAF, 2008).

Para os agricultores de Pelotas e municípios da Zona Sul do RS, a cultura do pessegueiro destacase pela importância econômica e social, pois, com uma estrutura fundiária baseada em minifúndios e com disponibilidade de mão-de-obra familiar, esses produtores encontram na fruticultura uma ótima alternativa de diversificação da matriz produtiva, a absorção da mão-de-obra familiar e a geração de renda em pequenas áreas (MADAIL, 2008). A região é o maior pólo de produção de pêssegos destinados ao processamento, abastecendo todo o mercado interno (JOÃO et al., 2002).

'Departamento de Fitossanidade, Faculdade de Agronomia "Eliseu Maciel”, Universidade Federal de Pelotas (UFPel), Campus Universitário s/n, CP 354, 96010-900, Capão do Leão, RS, Brasil. E-mail: clima@ufpel.tche.br. *Autor para correspondência. 
Para satisfazer essas demandas, os agrotóxicos se constituíram em uma tecnologia importante e amplamente difundida e têm sido a principal forma utilizada pelos persicultores para o manejo e o controle das principais pragas. Não se pode negar que esses produtos possibilitaram o aumento da produtividade agrícola e têm auxiliado no controle de diversas pragas, entretanto, seu uso desordenado e excessivo vem provocando diversos impactos sobre o meio ambiente e a saúde do trabalhador rural e do consumidor (CAMPANHOLA \& BETTIOL, 2003).

Nesse sentido, a Produção Integrada é apontada como uma alternativa para a produção de frutas de qualidade, pois utiliza práticas de manejo do solo e da planta de forma integrada, procurando equacionar os problemas por meio de uma visão multidisciplinar e não na aplicação de práticas isoladas, como ocorre na fruticultura convencional (FACHINELLO et al., 2001). As principais necessidades para a consolidação da Produção Integrada de Pêssego (PIP) incluem a ampliação da orientação quanto ao manejo integrado de insetos-praga e doenças, assim como da tecnologia de aplicação de agrotóxicos.

$O$ pêssego exige uma série de serviços, que inclui desde o cultivo e a manutenção do pomar, passando pela colheita, pelo o trabalho nas agroindústrias, até chegar à mesa do consumidor. No entanto, até o momento não se tem um diagnóstico completo sobre a cultura do pessegueiro. Os trabalhos até então realizados evidenciam a necessidade de maior detalhamento na caracterização do perfil do persicultor.

Com esse enfoque, os objetivos deste trabalho foram caracterizar as propriedades e obter dados para melhor diagnosticar a realidade sobre a exposição ocupacional a agrotóxicos na cultura do pessegueiro em Pelotas e em municípios da Zona Sul do Estado do Rio Grande do Sul, já que muitos agricultores da região estão envolvidos na cadeia produtiva desta fruta.

O estudo foi realizado na zona rural dos municípios de Pelotas, Canguçu e Morro Redondo, localizados na região Sul do Rio Grande do Sul, no período de maio a dezembro de 2007. A população alvo estudada foram os persicultores e os trabalhadores rurais que preparam e aplicam os agrotóxicos. Foi considerado trabalhador rural toda pessoa que realizava, no mínimo, 15 horas semanais (IBGE, 1992) em atividades de agricultura e pecuária para fins de comercialização e/ou consumo (FARIA et al., 1992).

$\mathrm{O}$ instrumento de coleta de dados empregado foi um questionário com 50 questões, a partir do qual foram entrevistados 135 persicultores (aproximadamente 10\% de cada município). Os dados foram obtidos em entrevistas in loco, realizadas aleatoriamente. Os entrevistados foram informados sobre o tema e os compromissos éticos da pesquisa, sendo que o consentimento verbal dos entrevistados foi um requisito para a realização da entrevista.

Para traçar o perfil do aplicador, foram coletadas informações contendo questões que podem ser subdivididas em seis grupos. O primeiro grupo está relacionado às características do entrevistado: sexo, idade, nível de escolaridade e relação de trabalho. O segundo está relacionado aos dados da propriedade rural onde o trabalhador exerce sua atividade: área cultivada (medida em hectares - ha), orientação e assistência técnica recebidas. O terceiro está associado ao uso de agrotóxicos: aquisição, preparo, aplicação e produtos mais utilizados. O quarto grupo está relacionado às medidas de proteção: uso de equipamentos de proteção individual (EPI). O quinto grupo está relacionado ao destino das embalagens vazias de agrotóxicos. As entrevistas foram realizadas no local de trabalho (pomar) e duraram em média 30 minutos. Ao final da entrevista, foram visitados os locais de armazenamento dos agrotóxicos e dos equipamentos de proteção e de descarte das embalagens vazias.

A classificação dos entrevistados segundo a faixa etária (Tabela 1) demonstrou que a média de idade dos persicultores é de 41 a 60 anos (51,1\%). Além da amostra estudada $(n=135)$, em $15,0 \%$ das propriedades foram identificadas 29 crianças com idade até 14 anos, que preenchiam o critério de trabalhador rural utilizado no estudo. Resultados similares foram obtidos por FARIA et al. (2000), em um estudo descritivo que avaliou o processo de produção rural e saúde na Serra Gaúcha, sendo que a região caracterizava-se pela diversidade das atividades agrícolas, especialmente a fruticultura, em que $18 \%$ da força de trabalho das propriedades seria constituída pelo segmento infantojuvenil. Quanto à escolaridade, a maioria dos entrevistados $(68,9 \%)$ estudou até a quinta série do Ensino Fundamental (Tabela 1). A dificuldade de ampliação do nível de escolaridade na região estudada está ligada às características das escolas rurais, que oferecem, no máximo, até quinta série do Ensino Fundamental. Ainda que a escolaridade dos trabalhadores rurais estudados seja maior do que a média gaúcha e a média brasileira para a população rural, é bastante inferior à média dos agricultores familiares norte-americanos, que geralmente possuem o Ensino Médio completo (ALAVANJA et al., 1996). O tamanho das propriedades visitadas era em $81,4 \%$ dos casos de 2 a 20 ha (Tabela 1), concordando com estudos realizados por FEHLBERG et al. (2001), em que a média das propriedades na zona rural de Pelotas era de 19ha. 
Tabela 1 - Caracterização da amostra de trabalhadores agrícolas, da propriedade rural, do tipo de assistência técnica recebida e de aspectos relacionados ao uso de agrotóxicos e medidas de proteção e destino das embalagens vazias durante a safra 2007/2008 na principal região produtora de pêssego para indústria do Brasil.

\begin{tabular}{|c|c|c|}
\hline Especificação & $\mathrm{N}$ & $\%$ \\
\hline Agricultores entrevistados & 135 & 100,0 \\
\hline \multicolumn{3}{|l|}{ Faixa etária (em anos) } \\
\hline Até 20 & 3 & 2,2 \\
\hline 21 а 40 & 47 & 34,8 \\
\hline 41 а 60 & 69 & 51,1 \\
\hline Mais de 60 & 16 & 11,9 \\
\hline \multicolumn{3}{|l|}{ Escolaridade } \\
\hline Nunca freqüentaram a escola & 8 & 5,9 \\
\hline Até a $5^{\circ}$ série do Ensino Fundamental & 93 & 68,9 \\
\hline Ensino Fundamental completo & 4 & 3,0 \\
\hline Ensino Médio incompleto & 21 & 15,6 \\
\hline Ensino Médio completo & 8 & 5,9 \\
\hline Ensino Superior & 1 & 0,7 \\
\hline \multicolumn{3}{|l|}{ Situação na lavoura } \\
\hline Proprietários & 105 & 77,8 \\
\hline Outras & 30 & 22,2 \\
\hline \multicolumn{3}{|l|}{ Área trabalhada } \\
\hline De 2 a 5 ha & 40 & 29,6 \\
\hline De 6 a 10ha & 42 & 31,1 \\
\hline De 11 a 20ha & 28 & 20,7 \\
\hline De 21 a 50ha & 19 & 14,1 \\
\hline De 51 a 100ha & 6 & 4,4 \\
\hline \multicolumn{3}{|l|}{ Aquisição do agrotóxico } \\
\hline Loja credenciada & 133 & 98,5 \\
\hline Outros & 2 & 1,5 \\
\hline \multicolumn{3}{|l|}{ Receituário agronômico } \\
\hline Sim & 4 & 2,9 \\
\hline Não & 131 & 97,1 \\
\hline \multicolumn{3}{|l|}{ Período de carência } \\
\hline Sim & 113 & 83,7 \\
\hline Não & 22 & 16,3 \\
\hline \multicolumn{3}{|l|}{ Destino das embalagens } \\
\hline Reciclagem/tríplice lavagem & 109 & 80,8 \\
\hline Queimadas & 16 & 11,8 \\
\hline Abandonadas lavoura & 4 & 3,0 \\
\hline Enterradas & 6 & 4,4 \\
\hline \multicolumn{3}{|l|}{ Uso EPI } \\
\hline Completo & 34 & 25,2 \\
\hline Incompleto & 74 & 54,8 \\
\hline Não usa & 27 & 20,0 \\
\hline
\end{tabular}

A maioria dos entrevistados são proprietários de suas terras (77,8\%). Quanto aos trabalhadores diaristas, estes dificilmente estão disponíveis para a realização de entrevista e pesquisa dessa natureza, mesmo sendo a cultura do pessegueiro uma das culturas da região em que ocorre intensa utilização de mão-de-obra temporária.
Com relação à orientação e à assistência técnica recebidas no manejo fitossanitário, a maioria dos entrevistados $(43,7 \%)$ relatou não ter recebido nenhum tipo de assistência técnica durante a safra 2007/ 2008, ou seja, desenvolvem as atividades a seu próprio modo (Tabela 1).

A aquisição dos agrotóxicos é feita junto a lojas credenciadas, porém, sem receituário agronômico (Tabela 1). Para alguns produtores, a leitura do rótulo dos produtos e da receita, quando fornecida pelo técnico, é desnecessária devido ao fato de eles já conhecerem o produto há bastante tempo. O preparo e a aplicação dos agrotóxicos eram feitos antes das 9 horas ou após as 17 horas, período em que as condições de clima são mais favoráveis à absorção e à translocação dos produtos.

Entre os agrotóxicos citados, destacam-se três que não são registrados para a cultura do pessegueiro, como o fungicida carbendazin (Derosal ${ }^{\circledR}$ 500 SC), aplicado principalmente na floração para controle da podridão-parda causada por Monilinia fructicola, sendo que este produto é utilizado por $88,2 \%$ dos persicultores, e o inseticida dimetoato $\left(\right.$ Perfekthion ${ }^{\circledR}$ ), empregado no controle de mosca-dasfrutas, que é utilizado por mais da metade dos persicultores (64,5\%). Destaca-se também o fungicida Benomyl ${ }^{\circledR}$ (benlate), cujo uso e comercialização estão proibidos no Brasil pelo Ministério da Saúde, porém, continua sendo usado por grande parte dos persicultores (70,3\%). A falta de assistência técnica compromete a utilização do produto adequado e os persicultores reclamam de não terem muitas opções de escolha, devido ao número muito reduzido de agrotóxicos registrados, disponíveis e com preço similar aos registrados para outras culturas. A observância do período de carência, que é o intervalo de segurança entre a última aplicação e a colheita, é fator importantíssimo no uso correto dos agrotóxicos, pois garante que os resíduos remanescentes nos alimentos estejam abaixo do limite máximo permitido para o consumo. Foi constatado que $83,7 \%$ dos persicultores dessa região observaram o período de carência (Tabela 1).

Com o objetivo de atender a Lei Federal 9.974, foi construída na região Sul do Rio Grande do Sul uma Central de Recebimento de Embalagens Vazias de Agrotóxicos. A unidade está em funcionamento desde junho de 2003, mesmo assim não existe na região uma prática única em relação ao descarte das embalagens de agrotóxicos. Dos 135 entrevistados, $80,8 \%$ guardam as embalagens para posterior recolhimento a ser realizado pela prefeitura ou pelas revendas de agrotóxicos (Tabela 1). Apesar da obrigatoriedade da devolução das embalagens vazias 
de agrotóxicos, após a tríplice lavagem, descasos e abusos foram constatados. Obviamente que as respostas, por serem espontâneas, refletem a conveniência pessoal.

Perguntados sobre medidas de segurança e proteção, 54,8\% informaram não usar o equipamento de proteção individual (EPI) completo para preparar e/ ou aplicar os agrotóxicos e 20,0\% informaram não usar nenhum tipo de proteção (Tabela 1). Esta situação tem sido observada em estudos realizados em outras regiões do nosso país (MACHADO, 1996; WAICHMAN, 2002). Os motivos alegados para não utilização do EPI completo, segundo relato dos entrevistados, ocorre em função do equipamento ser desconfortável e quente, dificultando o trabalho.

Os resultados mostram que de modo geral a cultura do pessegueiro em Pelotas e em municípios da Zona Sul do Estado do Rio Grande do Sul é praticada em pequenas propriedades, onde a mão-de-obra predominante é a familiar, sendo que no período de colheita é absorvida muita mão-de-obra temporária. A baixa escolaridade, associada à carência de orientação e assistência técnica, justifica algumas irregularidades no que diz respeito ao uso de agrotóxicos desde a compra até sua aplicação. A maioria dos entrevistados dá o destino adequado às embalagens vazias. A utilização de EPI padrão é uma prática incomum entre os aplicadores.

\section{REFERÊNCIAS}

ALAVANJA, M. C. R. et al. The agricultural health study. Environmental Health Perspectives, v.104, p. 362-369, 1996.

CAMPANHOLA, C.; BETTIOL, W. Métodos alternativos de controle fitossanitário. Jaguariúna, SP: Embrapa Meio Ambiente, 2003. 279p.

FACHINELLO, J.C. et al. Avaliação agronômica de um pomar de pessegueiro conduzido no sistema de produção integrada. Revista Brasileira de Fruticultura, v.23,p.138-142, 2001.
FARIA, N.M.X.. et al. Acidente de trabalho rural: um estudo em Tenente Portela, RS. Revista Brasileira de Saúde Ocupacional, v.20 p.45-49, 1992.

FARIA, N.M.X. et al. Processo de produção rural e saúde na serra gaúcha: um estudo descritivo. Cadernos de Saúde Pública, v.16, p.115-128, 2000.

FEHLBERG, M.F. et al. Acidentes de trabalho na zona rural de Pelotas, Rio Grande do Sul, Brasil: um estudo transversal de base populacional. Cadernos de Saúde Pública, v.7, p.13751381, 2001.

IBGE (Fundação Instituto Brasileiro de Geografia e Estatística). Pesquisa Nacional de Amostragem por Domicílios PNAD. Rio de Janeiro, 1992. 186p.

IBRAF (Instituto Brasileiro de Frutas). Produção de frutas frescas: cultura do pessegueiro. 2007. Capturado em 02 de fev. 2008. Online. Disponível na internet http:// www.ibraf.gov.br

JOÃO, P.L. et al. Levantamento da fruticultura comercial do Rio Grande do Sul. Porto Alegre: EMATER/ASCAR, 2002. 80p. (Série Realidade Rural, 28).

MACHADO, J.G.N. et al. Semiquantitative evaluation of dermal exposure to granulated insecticides in coffee (Coffea arabica L.) crop and efficiency of individual protective equipment. Bulletin of Environmental Contamination and Toxicology, v.57, p.946-951, 1996.

MADAIL, J.C.M. et al. Economia do pêssego no Brasil. In SIMPOSIO REGIONAL “TRES FRONTERAS”2., ARGENTINA-BRASIL-URUGUAY- EN EL CULTIVO DEL DURAZNERO, 2007, Las Brujas - Uruguay. Capturado em 02 de fev. 2008. On line. Disponível na internet http:// www.inia.org.uy/online/files/basesdatos

TIBOLA, C.S. et al. Análise da conformidade na adoção das normas de produção integrada de pêssego. Ciência Rural, v.37, p.1149-1152, 2007.

WAICHMAN, A.V. et al. Use and fate of pesticides in the Amazon State, Brazil: risk to human health and the environment. Environmental Science and Pollution Research. v.9, p.423-428, 2002. 